\title{
Fatty liver in children
}

This article was published in the following Dove Press journal:

Therapeutics and Clinical Risk Management

7 May 2009

Number of times this article has been viewed

\author{
Mandana Rafeey' \\ Fakhrossadat Mortazavi \\ Nafiseh Mogaddasi \\ Ghergherehchi Robabeh ${ }^{2}$ \\ Shamsi Ghaffari \\ Alka Hasani ${ }^{3}$ \\ 'Liver and Gastrointestinal Research \\ Center; ${ }^{2}$ Tabriz University (Medical \\ Science) Tabriz, Iran; ${ }^{3}$ Research Center \\ of Infectious Diseases \\ and Tropical Medicine
}

Correspondence: Mandana Rafeey Associate Professor of Pediatric

Gastroenterology, Liver

and Gastrointestinal Research Center,

Tabriz University (Medical Science),

Children's Hospital-Sheshglan Street,

Tabriz, Iran

Tel +989141146982

Fax +98 4II 5262280

Email mrafeey@yahoo.com
Aims: The aim of this study is to investigate the clinical and laboratory characteristics of nonalcoholic fatty liver disease (NAFLD) in a referral center of pediatrics in the northwest of Iran.

Methods: In this cross-sectional study all subjects aged between six months to 15 years that were referred to the sonography unit, were investigated for fatty liver from March 2005 to August 2006. Patients with fatty liver change underwent detailed clinical and laboratory evaluation.

Results: From 1500 children who were investigated, 34 subjects with sonographic evidence of fatty liver were enrolled in this study (2.3\%). The mean age was $6.53 \pm 3.07$ years. Elevated aspartate aminotransferase and alanine aminotransferase was detected in $38.2 \%$ and $47.1 \%$ of patients, respectively. The mean level of cholesterol was $461 \pm 182.23 \mathrm{mg} / \mathrm{dl}$ and $94.1 \%$ of patients had hypercholesterolemia. Total cholesterol level and serum aminotransferase levels had a significant positive correlation with severity of fatty liver $(p<0.05)$. Mean body mass index was significantly higher in patients with severe fatty liver $(\mathrm{p}<0.05)$.

Conclusion: The epidemiology of pediatric NAFLD should inform future attempts to develop evaluated screening protocols. Moreover, these data should guide efforts to delineate the pathophysiology of fatty liver in children.

Keywords: nonalcoholic fatty liver disease, steatohepatitis, obesity, children

\section{Introduction}

Although nonalcoholic fatty liver disease (NAFLD) had long been recognized as a frequent clinical entity, only recently has its importance as a potential cause of progressive and severe liver disease has been fully understood. ${ }^{1,2}$ The term 'nonalcoholic steatohepatitis' (NASH) is used when a fatty liver has progressed to a stage that includes inflammation (steatohepatitis) and scarring (steatonecrosis) of the liver. Unlike fatty liver, NASH is not considered a harmless condition, but rather a liver disease with the potential to cause cirrhosis, liver failure, and liver cancer. ${ }^{1-4}$ NAFLD is an increasingly recognized common, silent, and underdiagnosed syndrome. Patients are asymptomatic in early stages of the disease. ${ }^{5}$ But when the disease progresses and includes inflammation, steatohepatitis begins to progress, leading to the development of irreversible sequels. ${ }^{1,2}$

There are some challenges in determining the prevalence of NAFLD. Diagnosis requires liver biopsy, which is not feasible in a population-based study. Therefore, most studies use serum aminotransferase evaluation as a surrogate marker for fatty liver disease, ideally in conjunction with a negative marker for other types of fatty liver disease.

Imaging techniques such as ultrasonography have been helpful in diagnosis and assessing nonalcoholic fatty liver and steatosis with a specificity and sensitivity more than $90 \%{ }^{6}$ NASH may be more severe in children from certain ethnic groups such as

submit your manuscript | www.dovepress.con 
Hispanics and Asians. ${ }^{7}$ We have no documented information about fatty liver in Iranian children. The aim of this study is to investigate the clinical and laboratory characteristics of NAFLD in a referral center of pediatrics in the northwest of Iran.

\section{Materials and methods}

This study was performed for evaluation by sonography of fatty liver among children in Tabriz, Iran. This study was approved by the institution's Ethics Committee. All children aged between six months to 15 years, who came on outpatient visits for routine follow-up or growth evaluation and vaccination between March 2005 and August 2006, were enrolled on a voluntary basis after informed consent.

A trained hepatologist and sonographist evaluated abdominal ultrasonographic findings. Ultrasonography was done with a 3-7 $\mathrm{mHz}$ transducer and a high-resolution $\mathrm{B}$ mode scanner (Multi Frequency Convex Abdominal Transducer; Itochu Corporation, Tokyo, Japan). We evaluated four ultrasonographic findings, including hepatorenal echo contrast, bright liver, deep attenuation, and vessel blurring. ${ }^{8}$ The diagnosis of hepatorenal echo contrast was based on ultrasonographic contrast between the hepatic and right renal parenchyma at the right intercostals sonogram in the mid axillary line. The diagnosis of bright liver was based on abnormally intensive, high echoes arising from the hepatic parenchyma, and was graded on a three-grade scale as mild, moderate, or severe in accordance to intensity. ${ }^{8,9}$ Patients who had fatty liver in ultrasonographic evaluation were enrolled in this study.

Subjects with history of known liver disease including viral, metabolic, genetic, and autoimmune liver disease and patients with history of hepatotoxic drug intake (valproate, tetracycline, methotrexate, amiodorone, and prednisolone) and total parenteral nutrition were excluded before sonographic evaluation. Patients who had fatty liver with evidence of an underlying disease that could have caused secondary obesity such as leukemia, hypothyroidism, and nephrotic syndrome were excluded.

Patients with fatty liver change in sonography underwent detailed evaluation for viral, metabolic, and autoimmune hepatitis in Tabriz Medical University laboratory center. We surveyed hepatitis B and C virus antibody in all patients with fatty liver.

All subjects with fatty liver had blood samples taken in the morning after an overnight fasting for measurement of serum glucose, transaminases, total cholesterol, high-(HDL) and low-density lipoprotein (LDL) cholesterol and triglycerides.
Elevated liver tests defined as aspartate aminotransferase (AST) or alanine aminotransferase (ALT) levels more than 1.5 times above normal values (5-45 IU/L) for age.

Patients with fatty liver who were found to have a chronic liver disease including alpha-1-antitrypsin deficiency, Wilson's disease, autoimmune and viral hepatitis were excluded. In the remaining patients, body mass index (BMI) was calculated.

All data was gathered in a designed form containing demographic features, past medical history, drug history, results of physical exam and laboratory tests, and were analyzed by SPSS software (version 14 for Windows; SPSS Inc., Chicago, IL, USA). Chi-square and $t$-test were used for analysis. A p value less than 0.05 was considered significant.

The study was approved by the University Review Board, and informed consent was obtained from the subjects and their parents prior to assessment.

\section{Results}

From 1500 children who were investigated for NAFLD, after excluding patients with underlying diseases mentioned above, the prevalence of NAFLD was $2.3 \%$. None of the patients had diabetes mellitus.

The mean age of 34 subjects was $6.53 \pm 3.07$ years (range: six months to 15 years). Most (64.9\%) were male. There was no significant correlation between gender and sonographic report of fatty change or between the grade of fatty change and gender $\left(\chi^{2}=1 / 40, d f=1 ; p=0.236\right)$. Prevalence of fatty liver increased with age, ranging from $0.7 \%$ for ages $2-4$ years up to $17.3 \%$ for ages $12-15$ years. In the physical examination, mild hepatomegaly was the most frequent clinical finding and was detected in $48.6 \%$ of patients with fatty liver. $28 \%$ of study groups had some complaints such as fullness of epigastric area (11\%), mild right upper quadrant pain (8\%), and $9 \%$ complained of early satistification. From 34 children with fatty liver, 18 patients $(52.9 \%)$ had mild, 13 patients $(38.2 \%)$ had moderate, and three $(8.8 \%)$ had severe degrees of fatty liver. Elevated AST was detected in 13 patients (38.2\%) with a mean of $73 \pm 120.73 \mathrm{U} /$ lit (range 17-716). Elevated serum ALT levels was found in 16 patients (47.1\%) with a mean of $63 \pm 74.32 \mathrm{U} /$ lit (range 3-341). A strong positive correlation was demonstrated between ultrasonic severity of fatty liver and elevation of ALT and AST ( $p<0.05)$.

The mean level of cholesterol was $461 \pm 182.23$ (range: 91-950). Only two patients had normal total cholesterol $(5.9 \%)$ and the other 32 patients $(94.1 \%)$ had cholesterol levels more than normal value. Total cholesterol level had a significant correlation with severity of fatty liver $\left(\chi^{2}=9.53\right.$, $\mathrm{df}=2 ; \mathrm{p}=0.008)$. 
Thirty patients $(88.2 \%)$ had high HDL levels (mean: $98 \pm 54.49$; range: $24-230 \mathrm{mg} / \mathrm{dl}), 29$ patients $(87.90 \%)$ had high LDL levels (mean: $308 \pm 146.48$; range: $38-629 \mathrm{mg} / \mathrm{dl}$ ) and $44.1 \%$ of our patients had triglyceride levels more than $250 \mathrm{mg} / \mathrm{dl}$ (mean: $260.56 \pm 106.74$; range: 40-458) (Table 1).

Serum triglycerides and fasting plasma sugar were significantly higher in girls than in boys $(\mathrm{p}<0.05)$, but there was no significant relation between these parameters with grading of fatty liver $(\mathrm{p} \geq 0.05)$.

Mean of BMI in patients with fatty liver were $22.35 \pm 4.92$ (range: 15.6 to 33.3). Mean BMI was significantly higher in patients with severe fatty liver $(33 \pm 28)$ compared to patients with moderate and mild fatty liver structure $(\mathrm{p}<0.05)$.

\section{Discussion}

We believe that the current study is the first to determine the prevalence and identify the characteristics of fatty liver in pediatric population in our region. Histological features of fatty liver include steatosis alone or with combination of mixed inflammatory cell infiltration, hepatocyte ballooning and necrosis, Mallory's hyaline and fibrosis although portalbased injury is commonly seen in children..$^{10,11}$

In a study of school-aged children in northern Japan, overall prevalence of fatty liver was $2.6 \%$ by sonography with male dominancy. However, such prevalence has been found to be $10 \%-35 \%$ in obese children. ${ }^{3}$ Another study from Turkey showed that prevalence of fatty liver detected by sonography was $11.8 \%$ and elevated ALT and AST levels were found in $4.6 \% .{ }^{11}$ In this study elevated serum AST was detected in $38.2 \%$ and ALT in $47.1 \%$ of our patients.

Table I Laboratory finding of 34 children with fatty liver

\begin{tabular}{lll}
\hline Lab material & $\begin{array}{l}\text { Mean } \pm \text { SD } \\
\text { (normal value) }\end{array}$ & $\begin{array}{l}\text { Number of patients } \\
\text { with elevated value }\end{array}$ \\
\hline AST & $73 \pm 120.73$ & $13(38.2 \%)$ \\
& $(5-45 \mathrm{U} / \mathrm{L})$ & \\
ALT & $63 \pm 74.32$ & $16(47.1 \%)$ \\
& $(5-45 \mathrm{U} / \mathrm{L})$ & \\
Cholesterol & $461 \pm 182.23$ & $32(94 \%)$ \\
& $(<170 \mathrm{mg} / \mathrm{dl})$ & \\
Triglyceride & $261 \pm 106.7$ & $15(44.1 \%)$ \\
& $(<150 \mathrm{mg} / \mathrm{dl})$ & \\
LDL & $308 \pm 146.48$ & $29(87.9 \%)$ \\
& $(<110 \mathrm{mg} / \mathrm{dl})$ & \\
$\mathrm{HDL}$ & $98 \pm 54.49$ & $30(88.2)$ \\
& $(>60 \mathrm{mg} / \mathrm{dl})$ & \\
\hline
\end{tabular}

Abbreviations: ALT, alanine aminotransferase; AST, aspartate aminotransferase; $\mathrm{HDL}$, high-density lipoprotein; LDL, low-density lipoprotein; SD, standard deviation.
In a ultrasound-based study of Italian obese children, fatty liver was present in 38 (53\%) children, severe in nine, moderate in 16 , and mild in 13 patients and elevated serum aminotransferase were present in $25 \%{ }^{7}$

The exact prevalence of NASH/NAFLD is not well established. Information on its prevalence among children is scanty. Pooling data from studies were done mainly in medical centers and the prevalence of NAFLD in obese children has been reported to range from $20 \%$ to $77 \% .^{12,13}$ Investigators have used various methods to determine the prevalence of NAFLD in childhood. Ultrasound of the liver has been found to be a good screening tool for assessment of the degree of fat in the liver, but it does not correlate well with the degree of fibrosis. Joseph and colleagues reported a sensitivity of $89 \%$ and specificity of $93 \%$ for sonography in detecting steatosis, but a sensitivity of $77 \%$ and specificity of $89 \%$ in detecting fibrosis in the liver, respectively. ${ }^{14}$ The sensitivity and specificity of computed tomography (CT) and magnetic resonance imaging (MRI) varied from 54\%-93\% and 87\%-97\%, respectively according to the protocol followed. ${ }^{15}$ However CT scans or MRI are very costly and not feasible as routine work-up of suspected NAFLD. Liver biopsy remains the gold standard for diagnosis of steatosis and degrees of fibrosis. No imaging method is able to distinguish between simple steatosis and NASH and/or indicate the stage of fibrosis.

A study by Franzese and colleagues found that children with fatty liver in sonography had high BMI values, but could not demonstrate such a relationship.?

The epidemiology of pediatric NAFLD should inform future attempts to develop evaluated screening protocols. Moreover, these data should guide efforts to delineate the pathophysiology of fatty liver in children and adolescents.

\section{Conclusion}

Our study demonstrates that children with fatty liver may be asymptomatic or may present with nonspecific complaints. We found a significant correlation between elevation of ALT and AST, high levels of serum total cholesterol, and severity of obesity with grading of fatty liver.

\section{Acknowledgments}

The authors report no conflicts of interest in this work.

\section{References}

1. Ludwing J, Viggimo TR, Mcgill DB, et al. Nonalcoholic steatohepatitis: Mayo Clinic experiences with a hitherto unnamed disease. Mayo Clin Proc. 1980;55(7):434-438.

2. Moran JR, Ghishan FK, Halter SA, et al. Steatohepatitis in obese children: a cause of chronic liver dysfunction. Am J Gastroentrol. 1983;78(6):374-377. 
3. Marion A, Baker J, Dhawan A. Fatty liver disease in children. $B M J$. 2003;89(7):648-658.

4. Kimata $\mathrm{H}$. Prevalence of fatty liver in non-obese Japanese children with atopic dermatitis. Indian Pediatr. 2005;42:587-593.

5. Schwimmer J, Behling C, Newbury R, et al. Histopathology of pediatric non-alcoholic fatty liver disease. Hepatology. 2005;42(3):536-538.

6. Roberts E. Nonalcoholic steatohepatitis in children. Curr Gastroenterol Rep. 2003;5(3):253-259.

7. Franzese A, Vajro P, Argenziano A, et al. Liver involvement in obese children. Ultrasonography and liver enzyme levels at diagnosis and during follow-up in an Italian population. Dig Dis Sci. 1997;42(7):1428-1432.

8. Kim HC, Choi SH, Shin HW, et al. Severity of ultrasonographic liver steatosis and metabolic syndrome in Korean men and women. World $J$ Gastroenterol. 2005;11(34):5314-5321.

9. Liang RJ, Wang HH, Lee WJ, Liew PL, Lin JT, Wu MS. Diagnostic value of ultrasonographic examination for nonalcoholic steatohepatitis in morbidly obese patients undergoing laparoscopic bariatric surgery. Obes Surg. 2007;17(1):45-56.
10. Strauss RS, Barlow SE, Dietz WH. Prevalence of abnormal serum aminotransferases values in over weight and obese adolescents. J Pediatr. 2000;136:727-733.

11. Arsalan N, Büyükgebiz B, Öztürk Y, Çakmaçi H. Fatty liver in obese children: prevalence and correlation with anthropometric measurements and hyperlipidemia. Turk J Pediatr. 2005;47(1):23-27.

12. Chan DF, Li AM, Chu WC, et al. Hepatic steatosis in obese Chinese children. Int J Obes Relat Metab Disord. 2004;28:1257-1263.

13. Nobili V, Manco M, Ciampalini P, et al. Metformin use in children with nonalcoholic fatty liver disease: An open-label, 24-month, observational pilot study. Clin Ther. 2008;30(6):1168-1176.

14. Jeseph AE, Saverymuttu SH. al-Sam S, Ceek MG, Mazwell JD. Comparison of liver histology with ultrasonography in assessing diffuse parvenchymal liver disease. Clin Radiol. 1991;43:26-31.

15. Nobili V, Marcellini M, Devito R, et al. NAFLD in children; a prospective clinical-pathological study and effect of life style advice. Hepatology. 2006;44:458-465.
Therapeutics and Clinical Risk Management

\section{Publish your work in this journal}

Therapeutics and Clinical Risk Management is an international, peerreviewed journal of clinical therapeutics and risk management, focusing on concise rapid reporting of clinical studies in all therapeutic areas outcomes, safety, and programs for the effective, safe, and sustained use of medicines. This journal is indexed on PubMed Central, CAS,

\section{Dovepress}

EMBase, Scopus and the Elsevier Bibliographic databases. The manuscript management system is completely online and includes a very quick and fair peer-review system, which is all easy to use. Visit http://www.dovepress.com/testimonials.php to read real quotes from published authors.

Submit your manuscript here: http://www.dovepress.com/therapeutics-and-clinical-risk-management-journal 